\title{
Feeding affects phosphate fluxes in the symbiotic sea anemone Aiptasia pallida*
}

\author{
G. Muller-Parker ${ }^{1, * *}$, C. B. Cook $^{2}$, C. F. D'Elia ${ }^{1}$ \\ ${ }^{1}$ Chesapeake Biological Laboratory, University of Maryland, Box 38, Solomons, Maryland 20688-0038, USA \\ ${ }^{2}$ Bermuda Biological Station, Ferry Reach GE-01, Bermuda
}

\begin{abstract}
Phosphate uptake by the anemone Aiptasia pallida occurred only when anemones were starved and was due to the presence of endosymbiotic zooxanthellae. Anemones fed Artemia nauplii released $\mathrm{PO}_{4}{ }^{3-}$ at $0.26 \mu \mathrm{MPO}_{4}{ }^{3-}$, and showed no evidence of uptake at elevated concentrations $(0.66$ and $1.26 \mu \mathrm{M}$ ). In contrast, anemones maintained without food for $2 \mathrm{wk}$ to 1 mo took up $\mathrm{PO}_{4}{ }^{3-}$ at both 0.66 and $1.26 \mu \mathrm{M}$. The uptake of $\mathrm{PO}_{4}{ }^{3-}$ by anemones freshly collected from the field $\left(\left[\mathrm{PO}_{4}{ }^{3-}\right]=0.23 \mu \mathrm{M}\right)$ was greater than that of anemones fed daily in the laboratory, but less than that of 2-wk to 1-mo unfed anemones. Replacement of total (host and symbiont) phosphorus (P) solely from uptake of seawater $\mathrm{PO}_{4}{ }^{3-}$ at $0.66 \mu \mathrm{M}$ would require $374 \mathrm{~d}$ in fed anemones, indicating that this source is insignificant in comparison to ingested food. Corresponding times for 2 -wk and 1 -mo starved anemones average less than $8 \mathrm{~d}$, while those for field anemones average $50 \mathrm{~d}$. Field anemones thus appear to be intermediate between fed-daily and starved anemones with respect to phosphate uptake and P turnover. We conclude that the net flux of phosphate between A. pallida and seawater depends not only on the external seawater concentration, but also on the relative rates of $\mathrm{PO}_{4}{ }^{3-}$ regeneration by the host and $\mathrm{PO}_{4}{ }^{3-}$ uptake by the algae, both of which, in turn, are affected by the supply and assimilation of particulate food by the host anemone.
\end{abstract}

\section{INTRODUCTION}

The flux of inorganic nutrients between symbiotic associations and seawater has been of interest to marine scientists since the work of Yonge \& Nicholls (1931), who showed that reef corals containing endosymbiotic algae (zooxanthellae) retain or take up net amounts of $\mathrm{PO}_{4}{ }^{3-}$ at low environmental concentrations. Later studies using more sophisticated analytical procedures and radioisotopes confirmed these results and provided some indication of the kinetics of $\mathrm{PO}_{4}{ }^{3-}$ uptake (Yamazato 1970, D'Elia 1977, Propp 1981). Pomeroy \& Kuenzler (1969) showed that corals with zooxanthellae exhibited far greater abilities to retain P than nonsymbiotic tropical invertebrates. They evaluated $P$ retention by organisms in terms of turnover time $(\mathrm{P} / \Delta \mathrm{P})$. These

- Contribution No.2056, Center for Environmental and Estuarine Studies of the University of Maryland System; Contribution No. 1231 of the Bermuda Biological Station for Research

- Present address: Shannon Point Marine Center, Western Washington University, 1900 Shannon Point Rd, Anacortes, Washington 98221, USA studies and related investigations of nitrogen fluxes (Szmant-Froelich \& Pilson 1977, Muscatine \& D'Elia 1978, Wilkerson \& Muscatine 1984, Wilkerson \& Trench 1986 ) have shown that inorganic nutrients required by zooxanthellae are taken up from seawater by corals and other symbiotic cnidarians and are retained.

Inorganic nutrients for zooxanthellae may also be supplied in situ by the feeding activities of the host. This has been shown with laboratory-cultured corals and anemones maintained under controlled feeding schedules. Szmant-Froelich \& Pilson (1977, 1984) showed that the nitrogen flux of the temperate symbiotic coral Astrangia danae was greatly affected by the feeding history of the host; presumably feeding affects the size of nutrient pools available to zooxanthellae. Subsequent studies have shown that nutrient uptake by zooxanthellae isolated from the anemone Aiptasia pallida increases with degree of starvation of the host (D'Elia \& Cook 1988, Muller-Parker et al. 1989). These observations and those of Johannes et al. (1970) suggest that zooplankton are an important source of nutrients for zooxanthellae, and that the feeding activities of the host may affect the directional flux of nutrients in the natural environment. 
We have shown previously that zooxanthellae in Aiptasia pallida are affected by low nutrients and lack of host feeding (Cook et al. 1988). We now examine the flux of phosphate between A. pallida and seawater We assess the effects of feeding and seawater phosphate levels on $\mathrm{PO}_{4}{ }^{3-}$ fluxes, since $\mathrm{PO}_{4}{ }^{3-}$ uptake from seawater should depend on both the seawater $\mathrm{PO}_{4}{ }^{3-}$ concentration and the availability of $\mathrm{PO}_{4}{ }^{3-}$ in host internal pools. Phosphate fluxes and $P$ turnover rates of field populations were compared with those of cultured anemones maintained under different feeding regimes to estimate the $\mathrm{P}$ status of zooxanthellae of A. pallida in nature.

\section{MATERIALS AND METHODS}

Anemones. Anemones from clonal laboratory cultures were maintained in incubators at $25^{\circ} \mathrm{C}$ with a 12:12 L:D photoperiod at irradiance levels of 60 to 80 $\mu \mathrm{E} \mathrm{m}^{-2} \mathrm{~s}^{-1}$. Certain anemones were fed daily to repletion with Artemia nauplii, while others were kept without food in filtered $(>0.7 \mu \mathrm{m})$ low nutrient Sargasso seawater (GFSSW) for periods of up to several months as described by Cook et al. (1988). Aposymbiotic (algae-free) anemones were produced by a cold shock treatment (Steen \& Muscatine 1987), maintained in darkness, and fed every 2 to $3 \mathrm{~d}$.

To compare $\mathrm{PO}_{4}{ }^{3-}$ uptake by cultured anemones with that of anemones from the field, Aiptasia pallida was collected in Bermuda from Walsingham Pond, which was formed from a collapsed limestone cave. The pond is ringed by a flourishing mangrove community, and anemones were removed from a single mangrove root located in an unshaded area at less than $0.5 \mathrm{~m}$ depth. The similar patterns on the oral disk and tentacles of these anemones suggested that they were from a single clone developed through asexual reproduction. $\mathrm{PO}_{4}{ }^{3-}$ uptake by the field anemones was measured within 6 h after collection.

Nutrient analyses. $\mathrm{PO}_{4}{ }^{3-}$ determinations for both experimental incubations and seawater samples taken from Walsingham Pond and stock GFSSW were performed on either a Scientific Instruments M/CFA 200 continuous flow analyzer or a Technicon AutoAnalyzer II. All glassware, including incubation vessels, was pre- cleaned with $10 \% \mathrm{HCl}$ followed by 3 rinses with distilled water. Samples were frozen and subsequently analyzed for $\mathrm{PO}_{4}{ }^{3-}$ using a modification of the standard procedure (Technicon Industrial Method. No. 155-710 W/A), in which ascorbic acid was omitted from the color-forming reagent and added independently from the acid-molybdate stream. Inorganic nutrient concentrations of GF/Ffiltered Walsingham Pond water and GFSSW (Table 1) were determined using Technicon Industrial Methods No. 158-71 W/A for nitrate and nitrite and No. 154-71 W/ $\mathrm{B}$ for ammonium. Dissolved organic phosphorus was measured according to D'Elia et al. (1977).

Phosphate fluxes in symbiotic and aposymbiotic anemones. Phosphate fluxes of cultured anemones of different feeding histories and of field anemones were measured in Bermuda under standard culture conditions $\left(60\right.$ to $80 \mu \mathrm{E} \mathrm{m}^{-2} \mathrm{~s}^{-1}$ irradiance and $\left.25^{\circ} \mathrm{C}\right)$. Individual anemones in glass vials containing GFSSW were pre-acclimated to incubation conditions for at least $1 \mathrm{~h}$. At the start of each experiment, the seawater was replaced with $20.0 \mathrm{ml}$ of phosphate-enriched (with $\mathrm{KH}_{2} \mathrm{PO}_{4}$ ) GFSSW at final concentrations of $0.26,0.66$, and $1.26 \mu \mathrm{M} \mathrm{PO}_{4}{ }^{3-}$. Either 2.0 or $2.5 \mathrm{ml}$ samples of the incubation medium were withdrawn at 15 to $20 \mathrm{~min}$ intervals for up to $2 \mathrm{~h}$. The seawater removed during sampling was not replaced. The seawater was well stirred initially and prior to the removal of each sample, but remained undisturbed between sampling periods.

The previous incubation procedure was modified in some experiments to include continuous stirring. In these experiments, the incubation medium was stirred continuously by a magnetic stirbar placed beneath a plastic mesh platform supporting each anemone. Samples for phosphate determinations of the medium were withdrawn from the incubation vials by a peristaltic pump which delivered the sample stream directly to the autoanalyzer. These anemones were exposed to a higher light intensity than in the previous experiments $\left(400 u E \mathrm{~m}^{-2} \mathrm{~s}^{-1}\right)$.

We also examined the effect of recent feeding on phosphate fluxes in symbiotic and aposymbiotic anemones. Prior to sampling, uningested Artemia nauplii were removed from the incubation vials, and the seawater $\left(0.06 \mu \mathrm{MPO}_{4}{ }^{3-}\right)$ replaced at time zero. The seawater was sampled at periodic intervals for ca $20 \mathrm{~h}$ after feeding.

Table 1. Nutrient levels (umol 1-1) in filtered seawater obtained from Walsingham Pond on 29 May 1987 and of Sargasso seawater used for all phosphate uptake experiments. DOP: dissolved organic phosphorus; DIN: dissolved inorganic nitrogen; DIP: dissolved inorganic phosphorus

\begin{tabular}{|c|c|c|c|c|c|c|}
\hline $\begin{array}{l}\text { Seawater } \\
\text { source }\end{array}$ & $\mathrm{PO}_{4}^{3-}$ & DOP & $\mathrm{NH}_{4}^{-}$ & $\mathrm{NO}_{3}^{-}$ & $\mathrm{NO}_{2}^{-}$ & $\begin{array}{l}\text { DIN/DIP } \\
\text { (atomic) }\end{array}$ \\
\hline Walsingham Pond & 0.23 & $<0.01$ & 0.3 & 0.70 & $<0.03$ & 4.3 \\
\hline Sargasso (Hydrostation 'S') & 0.06 & $<0.01$ & $<0.3$ & 0.08 & 0.03 & 1.8 \\
\hline
\end{tabular}


Analysis of phosphate flux data. Phosphate uptake rates were calculated from third-order polynomial equations fitted to the raw $\mathrm{PO}_{4}{ }^{3-}$ concentration data. These equations were used to calculate fitted concentrations; the first derivative of the fitted curve at each sample point yields instantaneous rates of $\mathrm{PO}_{4}{ }^{3-}$ uptake (D'Elia \& Cook 1988). This approach minimizes both sampling and nutrient analytical errors that increase the variance in the concentration measurements. The fits of these curves to the raw data were quite good, with correlation coefficients generally greater than 0.97 . Phosphate uptake rates of anemones were derived from the fitted curves at equivalent seawater $\mathrm{PO}_{4}{ }^{3-}$ concentrations. The net change in $\mathrm{PO}_{4}{ }^{3-}$ concentration due to anemone uptake or release at each time point was calculated from the time zero $\mathrm{PO}_{4}{ }^{3-}$ content of the seawater sampled within $30 \mathrm{~s}$ of addition to each anemone, the amount of $\mathrm{PO}_{4}{ }^{3-}$ removed as samples to that time, and the amount of $\mathrm{PO}_{4}{ }^{3-}$ remaining in the seawater. Net changes in $\mathrm{PO}_{4}{ }^{3-}$ were normalized to biomass expressed as either zooxanthellar abundance (symbiotic anemones) or total protein (symbiotic vs aposymbiotic comparisons).

Biomass measurements. Following each experiment, individual anemones were homogenized with a teflon tissue grinder and algal numbers and total protein content of homogenates determined as in MullerParker (1984). Protein was measured by the method of Lowry et al. (1951), using bovine serum albumin as a protein standard. To relate phosphate uptake to P content of anemones, we measured the amount of $P$ and protein in other anemones maintained under similar conditions (fed daily, 2-wk starved, and 1 -mo starved), and used the ratio of $\mathrm{P}$ to protein ( $\mathrm{mg} \mathrm{P} / \mathrm{mg}$ protein) derived from these anemones to estimate the amount of $P$ in the experimental anemones. Measurements of total P (Aspila et al. 1976) and protein of homogenates from daily-fed and starved anemones yielded $\mathrm{P} /$ protein ratios ranging from 0.0299 ( $\pm 0.0018 \mathrm{SD}, \mathrm{n}=3$ ) to 0.0376 ( $\pm 0.0038 \mathrm{SD}, \mathrm{n}=3$ ), for fed to 1 -mo starved anemones respectively. We assumed that the ratio of $\mathrm{P} /$ protein for fed anemones applied to the field anemones. Recent measurements of $P$ and protein of other anemones from Walsingham Pond provide support for this assumption (Muller-Parker et al. unpubl.).

\section{RESULTS}

\section{Phosphate fluxes in symbiotic and aposymbiotic anemones}

To determine if phosphate uptake by anemones depends on the presence of zooxanthellae, we measured $\mathrm{PO}_{4}{ }^{3-}$ in continuously stirred seawater incubations of both symbiotic and aposymbiotic anemones starved for 2 wk. Symbiotic anemones removed $\mathrm{PO}_{4}{ }^{3-}$ from solution at an initial $\left[\mathrm{PO}_{4}{ }^{3-}\right]$ of $0.68 \mu \mathrm{M}$, whereas there was no uptake of $\mathrm{PO}_{4}{ }^{3-}$ by unfed algae-free anemones (Fig. 1). Since the uptake of $\mathrm{PO}_{4}{ }^{3-}$ appeared to be mediated by zooxanthellae, subsequent comparisons of phosphorus uptake between symbiotic anemones of differing nutritional history were based on data normalized to zooxanthellar abundance.

Phosphate uptake by symbiotic anemones suggested that light might affect uptake. To test this possibility, $\mathrm{PO}_{4}{ }^{3-}$ uptake by 2 wk starved anemones pre-incubated in the dark for $12 \mathrm{~h}$ was measured at 0.66 and $1.26 \mu \mathrm{M}$ and compared to similar experiments with 2-wk starved anemones in the light (Table 2). Phosphate uptake rates in the light and dark were not significantly different (t-test comparisons, $p>0.1$ ).

\section{Phosphate release by recently-fed anemones}

The $\mathrm{PO}_{4}{ }^{3-}$ fluxes of symbiotic and aposymbiotic daily-fed anemones were measured during the first $24 \mathrm{~h}$ after a meal of Artemia nauplii. Although both groups of fed anemones released $\mathrm{PO}_{4}{ }^{3-}$, symbiotic anemones released much less on a protein biomass basis than aposymbiotic anemones (Fig. 2). Most of the net release of phosphate by symbiotic anemones took place during the initial $3 \mathrm{~h}$ after feeding, with little further release for the duration of the experiment. In contrast, aposymbiotic anemones released $\mathrm{PO}_{4}{ }^{3-}$ continuously during the $24 \mathrm{~h}$ period. The amount of phosphate released by aposymbiotic anemones over $24 \mathrm{~h}$ was about 10 times that released by symbiotic anemones during the same period (Fig. 2).

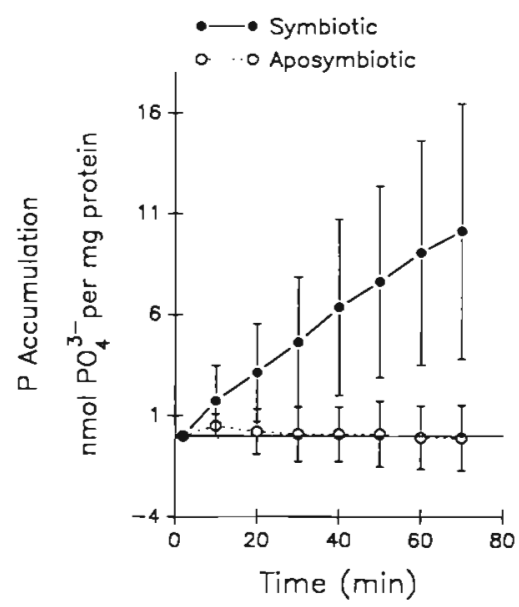

Fig. 1. Aiptasia pallida. Uptake of $\mathrm{PO}_{4}{ }^{3-}$ by 2 -wk starved aposymbiotic (algae-free) and symbiotic anemones at an initial $\mathrm{PO}_{4}{ }^{3-}$ concentration of $0.68 \mu \mathrm{M}$. Ordinate values represent the net amount of $\mathrm{PO}_{4}{ }^{3-}$ accumulated by anemones, normalized to anemone protein biomass. $N=3$ anemones; error bars are \pm 2 SEM 


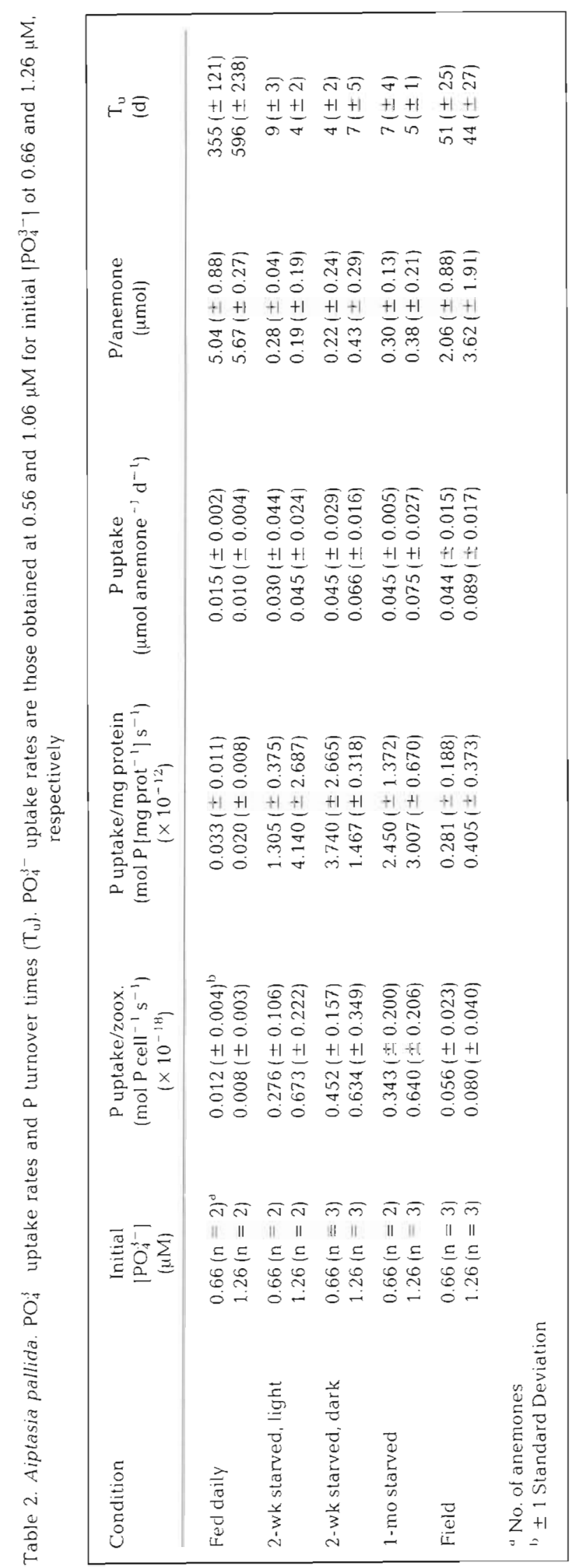

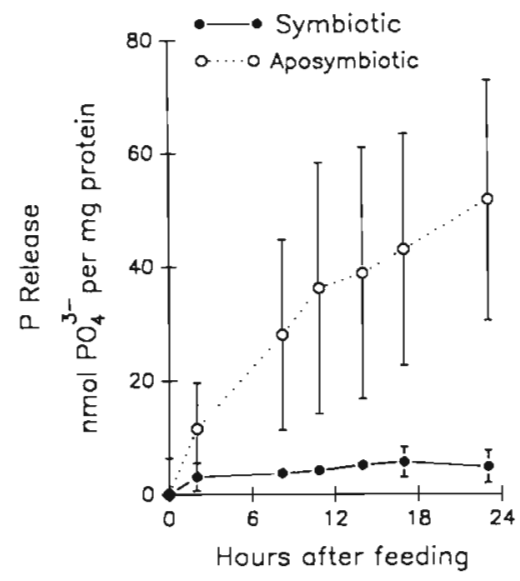

Fig. 2. Aiptasia pallida. $\mathrm{PO}_{4}{ }^{3-}$ release by symbiotic and aposymbiotic anemones after feeding. Anemones were fed Artemia nauplii, then the seawater was replaced and $\left[\mathrm{PO}_{4}{ }^{3-}\right]$ of the seawater measured during the next $20 \mathrm{~h}$. Ordinate values are the amount of phosphate released by fed anemones, normalized to anemone protein biomass. $N=3$ anemones; error bars are \pm 2 SEM

\section{Effect of starvation on phosphate fluxes in symbiotic anemones}

Changes in $\left[\mathrm{PO}_{4}{ }^{3-}\right]$ at 3 different initial $\mathrm{PO}_{4}{ }^{3-}$ concentrations are shown in Fig. 3 for intermittently stirred (every 10 to $15 \mathrm{~min}$ ) incubations of cultured anemones maintained without food for various periods of time. Actual concentrations (not corrected for biomass) are shown for representative anemones from each group. Sequential samples for a given anemone were consistent with the initial ( $30 \mathrm{~s}$ ) sample, but these initial samples did not always correspond to the $\mathrm{PO}_{4}{ }^{3-}$ concentrations measured in the incubation media prior to the addition of anemones (Fig. 3). Since there was no consistent pattern in this difference, either within or between experimental groups, we can offer no explanation for this discrepancy.

All anemones with the exception of the fed group removed $\mathrm{PO}_{4}{ }^{3-}$ from seawater at the 2 higher $\mathrm{PO}_{4}{ }^{3-}$ concentrations (Fig. 3a, b). Fed-daily anemones released phosphate at $0.66 \mu \mathrm{M}$ (Fig. 3b). At $0.26 \mu \mathrm{M}$ $\mathrm{PO}_{4}{ }^{3-}$, all anemones released $\mathrm{PO}_{4}{ }^{3-}$ for the first hour (Fig. 3c). This was followed by a return to near ambient levels for all but the fed anemones, which continued to release phosphate for the remainder of the experiment (Fig. 3c). Phosphate concentrations never dropped below $0.20 \mu \mathrm{M}$ in any experiment. Other experiments showed that 2 -wk starved anemones were not able to remove $\mathrm{PO}_{4}{ }^{3-}$ from ambient levels in GFSSW $(0.08$ $\mathrm{PO}_{4}{ }^{3-}$ ).

Both the feeding history of the anemones and the $\mathrm{PO}_{4}{ }^{3-}$ concentration affected the amount of phosphate 

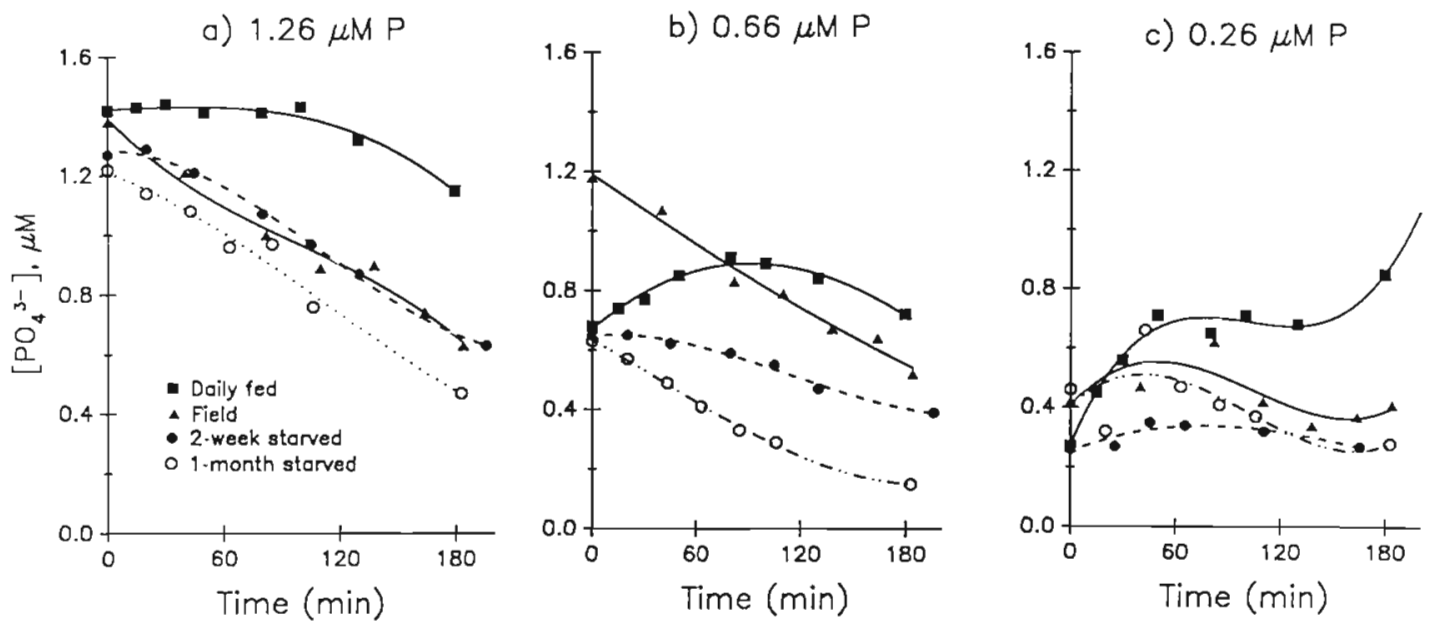

Fig. 3. Aiptasia pallida. $\left[\mathrm{PO}_{4}{ }^{3-}\right]$ of seawater containing fed, starved and field anemones. Initial $\mathrm{PO}_{4}{ }^{3-}$ concentrations were: (a) $1.26 \mu \mathrm{M}$, (b) $0.66 \mu \mathrm{M}$, (c) $0.26 \mu \mathrm{M}$. Seawater $\left[\mathrm{PO}_{4}{ }^{3-}\right.$ ] are actual concentrations for individual anemone incubations representative of each group, and are not corrected for biomass

either taken up or released by the anemones (Fig. 4). The amount of phosphate accumulated by anemones increased with degree of starvation. Anemones starved for 1 mo took up the most phosphate at all 3 concentrations, although the amount removed from the seawater was similar for anemones placed in 0.66 and $1.26 \mu \mathrm{M}$ phosphate (Fig. $4 \mathrm{a}, \mathrm{b}$ ). The amount taken up by 2 -wk starved anemones in $1.26 \mu \mathrm{M}$ phosphate seawater was double that taken up at $0.66 \mu \mathrm{M}$, resulting in similar uptake by 1 -mo and 2-wk starved anemones at $1.26 \mu \mathrm{M}$. Daily-fed anemones took up small amounts of phosphate at 1.26 uM (Fig. 4a), but released phosphate at the 2 lower concentrations (Fig. 4 b, c). At $0.26 \mu \mathrm{M}$, all but the 1-mo starved anemones released phosphate (Fig. 4c).

Phosphate fluxes of field anemones were intermedi- ate between those of 2 -wk starved and fed anemones at all phosphate concentrations (Fig. 4). Field anemones released phosphate at $0.26 \mu \mathrm{M}$, a $\mathrm{PO}_{4}{ }^{3-}$ concentration similar to that in Walsingham Pond and about 4 times that of GFSSW (Table 1).

\section{Phosphorus uptake and turnover rates of symbiotic anemones}

Phosphate uptake rates of the anemones were determined at 2 concentrations, 1.06 and $0.56 \mu \mathrm{M}$, for experiments conducted at 1.26 and $0.66 \mu \mathrm{M}$, respectively (Table 2). Uptake rates at these specified concentrations were close to the maximal uptake rates we observed. Uptake rates normalized to either anemone a) $1.26 \mu \mathrm{MP}$

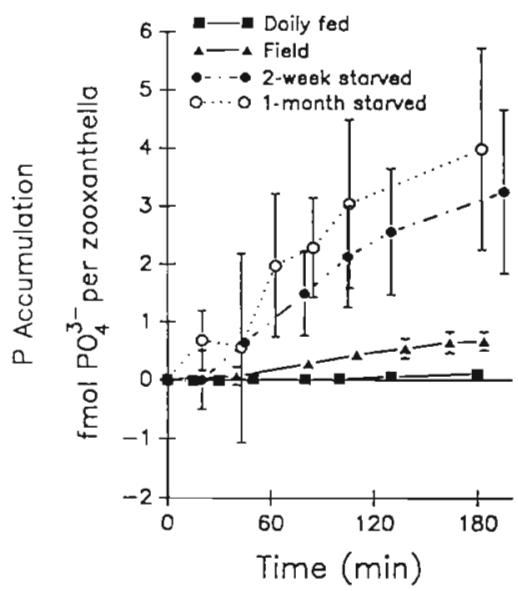

b) $0.66 \mu \mathrm{MP}$

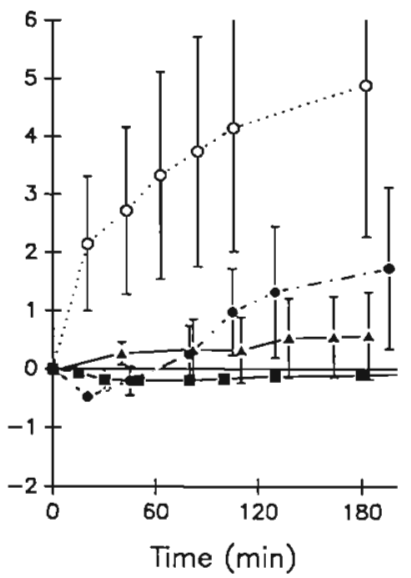

c) $0.26 \mu \mathrm{MP}$

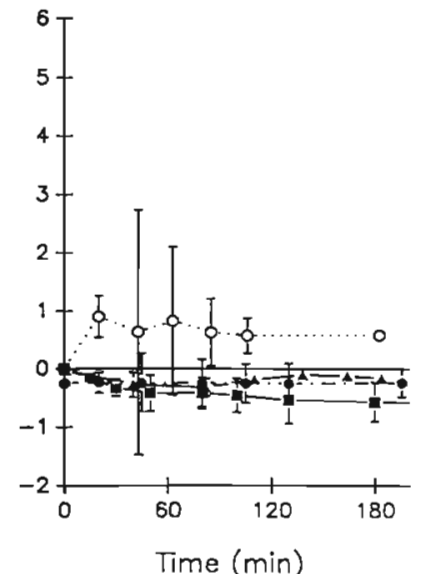

Fig. 4. Aiptasia pallida. Net flux of $\mathrm{PO}_{4}{ }^{3-}$ by fed, starved and field anemones at 3 initial $\mathrm{PO}_{4}{ }^{3-}$ concentrations: (a) $1.26 \mu \mathrm{M}$, (b) $0.66 \mu \mathrm{M}$, (c) $0.26 \mu \mathrm{M}$. Amount of $\mathrm{PO}_{4}{ }^{3-}$ taken up (or released) by anemones was normalized to number of zooxanthellae. $\mathrm{N}=3$ anemones; error bars are \pm 2 SEM 
protein or to number of zooxanthellae were much higher for unfed anemones than for anemones fed daily, with those of field anemones intermediate between the starved and fed anemones in the laboratory (Table 2).

We estimated $P$ turnover rates $(T)$ in Aiptasia pallida from both P-specific uptake rates $\left(T_{4}\right)$ and phosphate release rates following feeding $\left(T_{r}\right)$. $T_{u}$ is an estimate of the time required to completely replace anemone $P$ if dissolved phosphate was the only source of $P$, while $T_{r}$ is independent of $\mathrm{P}$ uptake and is comparable to turnover times calculated from excretion rates (Pomeroy \& Kuenzler 1969). Using our calculated uptake rates at 1.06 and $0.56 \mu \mathrm{M}$ and extrapolating these to a $24 \mathrm{~h}$ basis (Table 2), $\mathrm{T}_{\mathrm{u}}$ ranged from hundreds of days for fed anemones to under $10 \mathrm{~d}$ for 2-wk and 1-mo starved anemones (Table 2). Field anemones had intermediate turnover times averaging ca $50 \mathrm{~d}$. P turnover rates $\left(T_{r}\right)$ calculated from phosphate release rates (see Fig. 2) exceeded $29 \mathrm{~d}$ for symbiotic anemones, and were under $10 \mathrm{~d}$ for aposymbiotic anemones.

\section{DISCUSSION}

\section{Role of zooxanthellae in $\mathrm{PO}_{4}{ }^{3-}$ uptake by symbiotic invertebrates}

Uptake of phosphate by the symbiotic anemone Aiptasia pallida required the presence of zooxanthellae, since unfed aposymbiotic anemones did not remove $\mathrm{PO}_{4}{ }^{3-}$ from seawater (Fig. 1). P uptake has been previously attributed to zooxanthellae in both anemones (Smith 1939, Cates \& McLaughlin 1979) and corals (Yonge \& Nicholls 1931, Yamazato 1970, D'Elia 1977). Zooxanthellae are also responsible for the uptake and retention of dissolved inorganic nitrogen in symbiotic associations (Cates \& McLaughlin 1976, SzmantFroelich \& Pilson 1977, Muscatine et al. 1979, Muscatine \& D'Elia 1978, Muscatine 1980, Wilkerson \& Muscatine 1984, Zamer \& Shick 1987). Active uptake by zooxanthellae is implied by our results, but the potential contribution of active transport mechanisms in host tissue, particularly in the epithelia, was not determined. Light was not a significant factor in $\mathrm{PO}_{4}{ }^{3-}$ uptake by 2 -wk starved $A$. pallida, suggesting that phosphate uptake is not enhanced by algal photosynthesis.

The lower biomass-specific release of $\mathrm{PO}_{4}{ }^{3-}$ (Fig. 2) and the longer $P$ turnover times $\left(T_{r}\right)$ of symbiotic anemones relative to those of aposymbiotic anemones suggest that zooxanthellae promote the retention of phosphate by Aiptasia pallida. Algae may possibly stimulate the host to store inorganic phosphorus, or may be directly responsible for the uptake of phosphate in host tissue.

\section{Feeding history and nutrient fluxes in symbiotic invertebrates}

The feeding history of the anemones affected the flux of $\mathrm{PO}_{4}{ }^{3-}$. Phosphate was released by fed anemones (Fig. 2), while phosphate uptake increased with starvation (Fig.4). Phosphate uptake by algae isolated from fed and starved anemones was also directly related to the nutritional history of the anemone (Muller-Parker et al. 1989). Szmant-Froelich \& Pilson (1984) showed that unfed Astrangia danae exhibited slight ammonium uptake in the light, while excretion of ammonium by fed corals increased with feeding frequency. Uptake of the ammonium analogue ${ }^{14} \mathrm{C}$-methylamine by both intact Aiptasia pallida and isolated symbionts increased with the degree of starvation of the host (D'Elia \& Cook 1988). It thus appears that inorganic nutrient fluxes are influenced by the nutritional history of cnidarian hosts.

D'Elia (1977) previously measured dissolved P fluxes in several species of Pacific corals. He found that symbiotic corals in the light could reduce $\mathrm{PO}_{4}{ }^{3-}$ concentrations in seawater to as low as $0.03 \mu \mathrm{M}$. In our experiments, unfed anemones released $\mathrm{PO}_{4}{ }^{3-}$ at concentrations between 0.2 and $0.3 \mu \mathrm{M}$ (Fig. $3 \mathrm{c}$ ). The 'depletion-diffusion' hypothesis of dissolved nutrient uptake by symbiotic associations (D'Elia et al. 1983, D'Elia \& Cook 1988) implies that external concentrations at which the net flux of $\mathrm{PO}_{4}{ }^{3-}$ is zero are indicative of concentrations in host tissue. If this hypothesis is correct, these data suggest that even starving anemones have higher tissue levels of $\mathrm{PO}_{4}{ }^{3-}$ than do reef corals. This is supported by other measurements of the phosphorus and protein content of tissue from 2 corals (Montastrea annularis and Madracis mirabilis), where the $\mathrm{P}$ /protein ratio was 0.016 (Muller-Parker et al. unpubl.), about half that of Aiptasia pallida (see Materials and methods').

Uptake of $\mathrm{PO}_{4}{ }^{3-}$ was related to substrate concentration and feeding history (Table 2). We did not obtain Michaelis-Menten kinetics in any experiment, as has been typical of other studies of nutrient uptake by symbiotuc associations (e.g. Wilkerson \& Muscatine 1984, Wilkerson \& Trench 1986). While this may be due to the narrow range of substrate concentrations 10.06 to $1.28 \mu \mathrm{M})$ used in our experiments, the applicability of Michaelis-Menten kinetics to nutrient uptake relies on the measurement of initial uptake rates without the effect of accumulated product on uptake. This condition is rarely realized in these studies. Accordingly, we compared instantaneous uptake rates at 0.56 and $1.06 \mu \mathrm{M} \mathrm{PO}_{4}{ }^{3-}$ for experiments with initial levels of $\mathrm{PO}_{4}{ }^{3-}$ of 0.68 and $1.28 \mu \mathrm{M} \mathrm{P}$, respectively (Table 2). Uptake rates at these specified concentrations were close to the maximal uptake rates we observed. 
Nutrient uptake kinetics for intact associations are further complicated by the passage of nutrients through host tissue (Muscatine \& D'Elia 1978) and bidirectional fluxes (D'Elia 1977). Other experimental variables can affect the apparent measured uptake of nutrients, such as the time interval between samples, the volume of incubation medium relative to that of the experimental organism, or the degree of expansion of the organism. Uptake may be influenced by the biomass and algal density of individual anemones, parameters which are also affected by food supply (Clayton \& Lasker 1984, Muller-Parker 1985, Cook et al. 1988).

\section{Particulate feeding and supply of phosphorus to symbiotic zooxanthellae}

It is generally agreed that invertebrate hosts provide inorganic nutrients for symbiotic zooxanthellae (Muscatine \& Porter 1977), and that zooplankton feeding is an important source of nutrients (Johannes et al. 1970). Our experiments with field and laboratory-cultured Aiptasia pallida have shown that phosphate availability to zooxanthellae in field anemones is intermediate between that of daily-fed and starved laboratory populations. $\mathrm{PO}_{4}{ }^{3-}$ uptake rates and $\mathrm{P}$ turnover times of field anemones were less than those of anemones starved in the laboratory, but exceeded those obtained from fed cultures (Table 2). The relative importance of dissolved and particulate sources of $\mathrm{P}$ for zooxanthellae in field anemones could not be directly measured, but dissolved nutrient concentrations at the field site (Walsingham Pond) were much higher than those present in the stock Sargasso seawater used for starving anemones (Table 1), and exceeded values typically reported for other inshore waters in Bermuda (Morris et al. 1977, von Bodungen et al. 1982). We have not made similar measurements on anemone populations from habitats with more typical ambient low nutrient concentrations. Elevated concentrations could provide symbiotic algae with nutrients both through dissolved uptake, and by supporting a higher zooplankton density. Although the field anemones did not take up phosphate at levels typical of Walsingham Pond (Fig. 4c), concentrations of phosphate may vary over very small spatial and temporal scales.

We can infer the importance of particulate food as a source of $\mathrm{P}$ for zooxanthellae in symbiotic anemones from the relative times required for uptake-supported $P$ turnover $\left(\mathrm{T}_{\mathrm{u}}\right)$ and algal cell turnover. In daily-fed anemones, $\mathrm{T}_{\mathrm{u}}$ ranged from 355 to $596 \mathrm{~d}$ (Table 2), 20 to 40 times that of the $16 \mathrm{~d}$ turnover time of zooxanthellae in fed anemones calculated from Cook et al. (1988); these zooxanthellae clearly depend on food-derived $P$. In contrast, the $T_{\imath}$ of field anemones ranged from only
44 to $51 \mathrm{~d}$ (Table 2), very close to the algal mean turnover time of $68 \mathrm{~d}$ in field populations of the related anemone Aiptasia pulchella (Muller-Parker 1987). Phosphate uptake may thus potentially supply a significant fraction of the $P$ required by zooxanthellae in anemones under natural conditions. A similar analysis showed that the uptake of inorganic $N$ alone could support a coral doubling time of $100 \mathrm{~d}$ (D'Elia \& Webb 1977), although the relative importance of uptake could not be determined since the growth rates of the coral and zooxanthellae were unknown.

This study has shown that the uptake of $\mathrm{PO}_{4}{ }^{3-}$ by Aiptasia pallida is directly related to its nutritional history. Both the magnitude and direction of $\mathrm{PO}_{4}{ }^{3-}$ flux further depend on the supply of $\mathrm{PO}_{4}{ }^{3-}$ in the host versus that available in the surrounding seawater. Coupled with a similar dependency for ammonium fluxes (Szmant-Froelich \& Pilson 1984, D'Elia \& Cook 1988), these conclusions support the general view that the uptake of inorganic nutrients in symbiotic associations depends on zooxanthellae, but the direction and magnitude of the net flux is regulated by the relative supply of available nutrients in host tissue and the surrounding water. Yet to be determined are the specific mechanisms responsible for nutrient uptake. How are different nutrients, of differing charges (e.g. $\mathrm{NH}_{4}{ }^{+}$. $\mathrm{NO}_{3}{ }^{-}$), transported to zooxanthellae? What is the role (if any) of the animal membrane in nutrient uptake? How does the availability of a given nutrient affect the uptake of another nutrient? Our work suggests that feeding on zooplankton affects the size of nutrient pools in the host, but this has not been directly measured. The Aiptasia-zooxanthellae symbiotic association, easily cultured in the laboratory, should prove to be a useful experimental organism in which to examine these processes in more detail.

Acknowledgements. We thank J. A. Love, D. P. Ferrier, S. Refetoff and A. Patel for assistance, and K. Webb for helpful comments on the manuscript. This research was supported by grants from the National Science Foundation: OCE-8719701 (GMP), OCE-8602190 and OCE-8718257 (CBC); and OCE8515699 (CFD)

\section{LITERATURE CITED}

Aspila, I., Agemian, H., Chau, A. S. (1976). A semi-automated method for the determination of inorganic, organic and total phosphate in sediments. Analyst 101: 187-197

Cates, N., McLaughlin, J. J. A. (1976). Differences of ammonia metabolism in symbiotic and aposymbiotic Condylactus and Cassiopea spp. J. exp. mar. Biol. Ecol. 21: 1-5

Cates, N., McLaughlin, J. J. A. (1979). Nutrient availability for zooxanthellae derived from physiological activities of Condylactus spp. J. exp. mar. Biol. Ecol. 37: 31-41

Clayton, W. S. Jr, Lasker, H. R. (1984). Host feeding regime and zooxanthellal photosynthesis in the anemone, Aiptasia 
pallida (Verrill). Biol. Bull mar. biol. Lab., Woods Hole 167: $590-600$

Cook, C. B., D'Elia, C. F., Muller-Parker, G. (1988). Host feeding and nutrient sufficiency for zooxanthellae in the sea anemone Aiptasia pallida. Mar Biol. 98: 253-262

D'Elia, C. F. (1977). The uptake and release of dissolved phosphorus by reef corals. Limnol. Oceanogr. 22: 301-315

D Elia, C. F., Cook, C. B. (1988). Methylamine uptake by zooxanthellae-invertebrate symbioses: insights into host ammonium environment and nutrition. Limnol. Oceanogr. 33: 1153-1165

D'Elia, C. F., Domotor, S. L., Webb, K. L. (1983). Nutrient uptake kinetics of freshly isolated zooxanthellae. Mar Biol. 75: 157-167

D'Elia, C. F., Steudler, P. A., Corwin, N. (1977). Determination of total nitrogen in aqueous samples using persulfate digestion. Limnol. Oceanogr. 22: 760-764

D'Elia, C. F., Webb, K. L. (1977). The dissolved nitrogen flux of reef corals. Proc. 3rd Int. Coral Reef Symp. 1. 325-330.

Johannes, R. E., Coles, S. L., Kuenzel, N. T. (1970). The role of zooplankton in the nutrition of some scleractinian corals. Limnol. Oceanogr 15: 579-586

Lowry, O. H., Rosebrough, N. J., Farr, A. L., Randall, R. (1951). Protein measurement with the Folin phenol reagent. J biol. Chem. 193: 265-276

Morris, B., Barnes, J., Brown, F., Markham, J. (1977). The Bermuda Marine Environment. A report of the Bermuda inshore waters investigations 1976-1977. Spec. Publs. Bermuda Biol. Stn Res. No. 15

Muller-Parker, G. (1984). Photosynthesis-irradiance responses and photosynthetic periodicity in the sea anemone Aiptasia pulchella and its zooxanthellae. Mar. Biol. 82 225-232

Muller-Parker, G. (1985). Effect of feeding regime and irradiance on the photophysiology of the sea anemone Aiptasia pulchella. Mar. Biol. 90: 65-74

Muller-Parker, G. (1987). Seasonal variation in light-shade adaptation of natural populations of the symbiotic sea anemone Aiptasia pulchella (Carlgren, 1943) in Hawaii. J. exp. mar. Biol. Ecol. 112: 165-183

Muller-Parker, G., D'Elia, C. F., Cook, C. B. (1989). Nutrient limitation of zooxanthellae: effects of host feeding history on nutrient uptake by isolated algae. Proc. 6th int. Coral Reef Symp. (in press)

Muscatine, L. (1980). Uptake, retention, and release of dissolved inorganic nutrients by marine alga-invertebrate associations. In: Cook, C. B., Pappas, P. W., Rudolph, E. D. (eds.) Cellular interactions in symbiosis and parasitism. Ohio State Univ. Press, Columbus, p. 229-244

Muscatine, L., D'Elia, C. F. (1978). The uptake, retention, and

This article was presented by Professor K. R. Tenore,

Solomons, Maryland, USA release of ammonium by reef corals. Limnol. Oceanogr. 23: $725-734$

Muscatine, L., Masuda, H., Burnap, R. (1979). Ammonium uptake by symbiotic and aposymbiotic reef corals. Bull. mar. Sci. 29: 572-575

Muscatine, L., Porter, J. W (1977). Reef corals: mutualistic symbioses adapted to nutrient-poor environments. BioSci. 27: $454-460$

Pomeroy, L. R., Kuenzler, E. J. (1969). Phosphorus turnover by coral reef animals. In: Nelson, D. J., Evans, F. C. (eds.) Symposium on radioecology. Nat. Tech. Info. Serv., Springfield, p. 474-482

Propp, M. V (1981). Release and uptake of ammonium, nitrate, and orthophosphate by some corals. Soviet J. mar. Biol. 7: 198-204

Smith, H. G. (1939). The significance of the relationship between actinians and zooxanthellae. J. exp. Biol. 16: $334-345$

Steen, R. G., Muscatine, L. (1987). Low temperature evokes rapid exocytosis of symbiotic algae by a sea anemone. Biol. Bull. mar. biol. Lab., Woods Hole 172: 246-263

Szmant-Froelich, A., Pilson, M. E. Q. (1977). Nitrogen excretion by colonies of the temperate coral Astrangia danae with and without zooxanthellae. Proc. 3rd int. Coral Reef Symp. 1: $417-423$

Szmant-Froelich, A., Pilson, M. E. Q. (1984). Effects of feeding frequency and symbiosis with zooxanthellae on nitrogen metabolism and respiration of the coral Astrangia danae. Mar. Biol. 81: 153-162

von Bodungen, B., Jickells, T. D., Smith, S. R., Ward, J. A. D., Hillier, G. B. (1982). The Bermuda Marine Environment. Vol. III. The final report of the Bermuda Inshore Waters Investigations 1975-1980. Spec. Publs Bermuda Biol. Stn Res. No. 18

Wilkerson, F. P., Muscatine, L. (1984). Uptake and assimilation of dissolved inorganic nitrogen by a symbiotic sea anemone. Proc. R. Soc. Lond. B 221: 71-86

Wilkerson, F. P., Trench, R. K. (1986). Uptake of dissolved inorganic nitrogen by the symbiotic clam Tridacna gigas and the coral Acropora sp. Mar. Biol. 93: 237-246

Yamazato, K. (1970). Calcification in a solitary coral, Fungia scutaria L. in relation to environmental factors. Bull. Sci. Eng. Div., Univ. Ryukyus (Okinawa) 13: 57-122

Yonge, C. M., Nicholls, A. G. (1931). Studies on the physiology of corals. 4. The structure, distribution and physiology of zooxanthellae. Scient Rep. Gt Barrier Reef Exped. 1: $135-176$

Zamer, W. E., Shick, J. M. (1987). Physiological energetics of the intertidal sea anemone Anthopleura elegantissima II. Energy balance. Mar Biol. 93: 481-491

Manuscript first received: February 16, 1989

Revised version accepted: November 8, 1989 